\title{
Customer use of virtual channels in multi-channel services: Does type of activity matter?
}

\author{
Rui Sousa (rsousa@porto.ucp.pt) \\ Catholic University of Portugal (Porto) \\ Marlene Amorim \\ GOVCOPP, University of Aveiro \\ Elliot Rabinovich \\ Arizona State University
}

\begin{abstract}
This paper examines whether customer use of virtual channels varies with the type of service activities (e.g. information search, transactions) they engage in. Based on data from a multichannel bank, we first investigate the impact of customer distance to the nearest branch on the degree of use of virtual channels (internet and phone, aggregated), for different types of activities. Second, when customers do resort to virtual channels to conduct activities, we look at their relative channel preferences (internet vs. phone) for different types of activities. The results inform design decisions about which activities to offer through virtual channels.
\end{abstract}

Keywords: service operations, service design, multi-channel services.

\section{Introduction}

In recent years, many service providers have set-up virtual channels of service delivery, based most notably on the internet and the phone, to complement their existing physical facilities. Retail banks, in particular, have led the adoption of new channels, offering customers numerous alternatives for conducting banking activities (Xue et al, 2011). The success of such multichannel strategies will be determined by the ability of service providers to align service design decisions with customers' multichannel behavior (Dabholkar, 2000). Several studies have tried to understand the factors influencing how customers use virtual channels in the context of multichannel services (e.g., Burke, 2002). Whereas these studies have looked at the intensity with which customers use virtual channels, they typically do not address channel use for different types of service activities. In order to close this research gap, this study attempts to understand whether customer use of virtual channels varies with the type of activities (e.g. information search, transactions, etc.) offered across virtual and physical channels.

Addressing channel use at the level of service activities is important because customers value using different channels when engaging in different types of activities. 
Past research has suggested that customers are likely to select channels with increased personal contact to conduct complex activities in order to obtain advice and reassurance (Xue et al, 2007). In financial services, for example, branches are perceived to be more adequate to conduct complex activities (e.g. contracting of financial products) because they enable face to face interactions with service employees (Frambach et al., 2007, McNight et al., 2002). For activities which involve the access and analysis of substantial information, virtual channels such as the internet, are typically perceived as superior to physical channels (Coelho and Easingwood, 2008). The degree of fit between the type of activity the customer intends to perform and the different channels is therefore an important factor influencing customer channel preferences (Black et al., 2002).

We believe that addressing channel utilization for distinct service activities may help explain some of the conflicting findings about the relationship between the accessibility of physical channels by consumers and consumers' use of virtual channels. It is frequently hypothesized that virtual channels can be used as substitutes for visits to physical channels, particularly when the access to service locations is difficult or costly (Weltevreden, 2006). However, recently, Xue et al. (2011) used branch density as a measure of accessibility of physical channels, only to find that this accessibility is not as important in explaining the use of virtual channels. We submit that the effect of channel accessibility may differ across service activities because the superior convenience, information availability and accessibility offered by virtual channels (McKnight et al., 2002) are not equally important for all types of activities.

Therefore, we address two questions. First, we investigate the impact of customer distance to the nearest physical facility on the degree of use of virtual channels (internet and phone, aggregated), for different types of activities (RQ1). Second, when customers do resort to virtual channels to conduct activities, we look at their relative channel preferences (internet vs. phone) for different types of activities (RQ2). Underlying these questions is the notion that customers' comparative assessment between virtual and physical channels, as well as between phone and internet, will differ for different types of activities.

\section{Literature review and research questions}

\section{Customer channel choice framework}

In choosing channels, customers consciously evaluate different choices available to them (Tse and Yim, 2001). A channel's attractiveness depends on the value (benefits minus costs) it can offer to each customer, compared to other alternatives (van Birgelen et al, 2006). We submit that there are two main factors influencing customers' channel use for a given service activity (Figure 1): i) customers' intrinsic attributes; ii) the fit between activity type and channel attributes.

Concerning the first factor, research has uncovered numerous intrinsic customer attributes affecting customer channel choices. This long list includes: i) demographic, socio-economic and lifestyle attributes (e.g., Ding et al., 2007; Schoenbachler and Gordon, 2002; Venkatesan et al., 2007); ii) attitudes towards technology (Black et al., 2002; Boyer and Frohlich, 2006; Dabholkar and Bagozzi, 2002); iii) past channel experience (when and how the customer has interacted in the past), including customer channel switching costs/inertia (Frambach et al., 2007; Gensler et al., 2007; Schoenbachler and Gordon, 2002); iv) ability to engage in self-service (customer 
efficiency, Xue et al, 2011); v) volume of customer's service demand (Xue et al, 2011); vi) customer channel access (Xue et al, 2011); vii) customer situational factors: a given customer may make different channel choices to execute a given activity according to the situational aspects at the particular time of choice; a wide variety of situational aspects can influence channel choice such as time pressure, degree of mobility, and geographical location (Monsuwé et al, 2004). Several studies have shown that customers can be heterogeneous across these attributes (e.g., Boyer and Frohlich, 2006; Iqbal et al., 2003; Xue et al, 2007). Consequently, for a given activity, different customers may have different requirements for MC service delivery and may value different channel attributes.

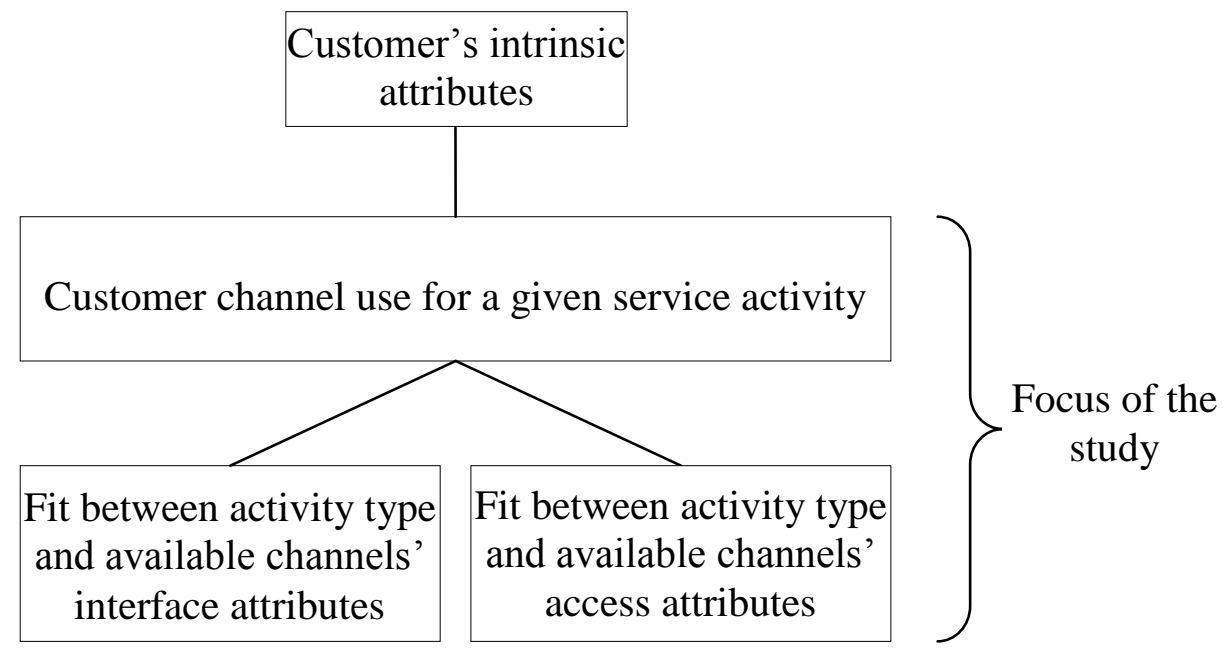

Figure 1. Framework of customer channel choice.

The focus of our study is on the second factor, the fit between activity type and channel attributes. The theory of task/technology fit (Goodhue, 1995; Goodhue and Thompson, 1995; Zigurs and Buckland, 1998) highlights the need for fit between the user's task specific requirements and technology characteristics. Different channels have intrinsically different characteristics. In general, virtual channels offer increased convenience, transactional efficiency, information availability and accessibility, while physical channels rank higher in terms of the richness and complexity of customer interactions or the level of security that they can offer (McKnight et al., 2002; Patricio et al., 2008). As a consequence, channels differ in their ability to support different types of activities.

Most research to date tends to take a customer-centric view, addressing channel use at an aggregate level. Specifically, little research has distinguished between different types of activities.

\section{Channel attributes}

We distinguish between two dimensions of channel attributes that are determinant for customer channel choices: channel accessibility and channel interface.

Channel accessibility concerns the set-up effort (cost, amount of time, etc) that is required to access a channel for use. In the specific context of financial services, 
accessibility is considered a key aspect of customer perceived channel performance (Patrício, Fisk and Falcão e Cunha, 2003). According to Seiders et al. (2007) accessibility is a particular aspect of service convenience, which is salient at the service access phase. Whereas in early studies accessibility was essentially related to the geographical proximity of service facilities to customers, nowadays the concept embraces the physical location, operating hours, as well as the availability online or by phone of a service (Meuter, Ostrom, Roundtree and Bitner, 2000, Seiders, Berry and Gresham, 2000). Virtual channels, such as the internet and the phone, offer customers alternatives to overcome the geographical constraints of accessing a service, and convey also the possibility of accessing a service beyond the usual office hours of traditional physical channels. In recent years, the widespread adoption of wireless internet and mobile phones, has contributed to increase the accessibility of some channels, such as the Internet, or phone call centers, to virtually anyone across the globe, whereas physical channels, such as bank branches, are stationary and therefore only available to a geographically limited consumer base (Dholakia et al., 2010).

Channel interfaces are very heterogeneous in what regards the nature of interaction and communication, i.e. the customer-provider exchanges that they support. Important differences regard the capabilities to deal with the exchange of information, which represents the core process flows in the context of financial services. For example, some virtual channels only allow for asynchronous communications. In contrast, other channels such as branches or the phone enable real-time synchronous communication with the service provider. These differences can affect how much information is available to a consumer and how this information is utilized (Dholakia, Bagozzi, and Klein Pearo, 2004).

Channel interface differences have been summarized around the concept of "media richness", i.e. the capacity of a given media of communication to process rich information, which is determined by its capacity for immediate feedback, the multiple cues and senses involved, language variety, and personalization (Lengel and Daft, 1988). This approach allows for a classification of media on a continuum describing their relative richness: face-to-face is the richest medium, followed by telephone, voice messaging, electronic mail, and Web sites (Rice, 1992).

Whereas the Internet, or the phone, enable customers to avoid the effort of accessing a physical channel, customers are likely to continue to use stores, bank branches, etc., for some service activities. In some circumstances, customers will prefer services delivered trough face-to-face interactions, driven by needs such as customization quality, or the avoidance of perceived risk in delivery (Cho and Park, 2003). Likewise, in what regards virtual channels, in some instances, customers will persist to prefer the phone channel over the Internet, for some service activities, because it enables some level of personal contact (Patrício, Fisk and Falcão e Cunha, 2011). Aspects related to the volume and frequency with which a service activity will be conducted by the customer can also de taken into account in this evaluation. In retail settings, some research results suggest that customers are more likely to use virtual channel as substitutes to the physical store for services which involve a high volume of transactions (Weltevreden, 2007). 


\section{Activity attributes}

Several studies have suggested the need to observe the characteristics of distinct products/and service processes in order to specify adequate channel interfaces. Boyer et al. (2002) proposed a classification of service processes based on volume and complexity, and suggested a strategic alignment between the distinct services and different types of mediation for a service encounter (e.g. face-to-face, person/voice telephone, technology based, etc.).

Several characterizations distinguish service activities according to their complexity, comprising a number of different aspects. In this regard, Haynes et al. (1990) identified two dimensions to classify service activities: the degree of operational complexity and the degree to which an activity is mechanistic or organic. Operational complexity is related to the cost, sophistication and content of the technical core aspect of the service being delivered. Mechanistic activities involve hierarchical control and communication, precise definition of functional processes and in general rule-governed operations/activities. On the contrary, organic activities are associated with interaction with others, and the delivery of information and advice rather than decisions. In a similar approach, Pieterson and van Dijk (2007) identified "task complexity" and "task ambiguity" as key determinants of customers' channel choices. Task complexity is related to the number of interrelated steps in a task. The more steps or aspects in a single task, the more complex the situation gets. The authors suggest that the perceived complexity affects what channels people use, such that in most cases people prefer the more personal channels for complex problems. Task ambiguity can be seen as the degree to which multiple interpretations of a task exist. Ambiguity is often expressed in 'not knowing what the problem is and how to solve it. Also in these situations, the authors suggest that customers are less likely to rely in automated channels.

\section{Research questions}

The literature review shows that channels and service activities may have different attributes that are relevant for customer channel use. Thus, customers' comparative assessment between virtual and physical channels, as well as between phone and internet, will differ for different types of activities. Accordingly, we investigate the impact of customer distance to the nearest physical facility on the degree of use of virtual channels (internet and phone, aggregated), for different types of activities (RQ1). Second, when customers do resort to virtual channels to conduct activities, we look at their relative channel preferences (internet vs. phone) for different types of activities (RQ2).

\section{Methods and data analysis}

We examined customers' utilization of phone and internet channels for banking activities with a multichannel retail bank in the EU. The bank employed branches, phone and internet as the main channels, offering all banking activities across all channels, whenever possible. We collected data for approximately 200.000 active users of all channels. For each customer, we collected: i) socio-demographic data (including distance to assigned branch); ii) data for the longevity of utilization of virtual channels; and iii) the number of times that the customer performed each of the selected banking activities through the internet or the phone during the calendar year of 2009. Data were collected 
from the bank's customer database and back office IT systems which record customers' utilization of each virtual channel.

Data analysis involved a preliminary classification of the selected activities into four categories, by increasing order of complexity: access to information (I), transactions (T), account management (M), and management of financial applications (A). This classification reflected the level of complexity associated with non-routine or nonstandard customer interactions (van Birgelen et al., 2006), and the requirement of specific customer knowledge or the analysis of complex information. These different types of activities differed also in the overall volume and frequency with which they were conducted by customers. Information activities represented the higher volume of customer interactions, followed by $\mathrm{T}, \mathrm{M}$ and A activities. We developed measures for capturing the degree of relative utilization of the internet and the phone. These measures weighed the volume of internet usage (total of activities $\mathrm{I}+\mathrm{T}+\mathrm{M}+\mathrm{A}$ conducted in the internet) against the total volume of utilization of both virtual channels (total of activities $\mathrm{I}+\mathrm{T}+\mathrm{M}+\mathrm{A}$ conducted in both virtual channels).

We employed regression analyses to test: i) the relationship between the distance of customers to the assigned branch and the utilization of virtual channels, at an aggregate level as well as for each type of service activity (RQ1); ii) the existence of differences in the relative use of each virtual channel (internet vs. phone) across the distinct types of service activities (RQ2).

\section{Results}

Preliminary results confirm our expectations about the importance of the characteristics of activities to explain differences in the utilization of virtual channels.

Concerning RQ1, the effect of customer distance to the assigned branch on the aggregate level of use of virtual channels (all activities) was not significant. However, the effect of distance at the level of each type of activity was positive and significant for the transactions $(\mathrm{T})$ and account management $(\mathrm{M})$ activities. This effect was stronger for $\mathrm{T}$. This suggests that a decrease in physical channel accessibility can lead customers to use virtual channels as substitutes for branches to conduct some activities, notably those that are relatively routine, i.e. have a smaller degree of complexity and represent a substantial volume of customer interactions with the bank.

Concerning RQ2, results suggest that the relative use of internet vs. phone is significantly different for different types of activities; in general, the preference for the internet increases as the complexity of the activities decreases, with the exception of I. Whereas the internet was still the dominant channel for activities related to the access to information, the degree relative use of internet vs. phone was inferior when compared to T, $\mathrm{M}$ and A activities. These results suggest the need to further investigate the factors which influence channel choice for information related activities. Customer situational variables might play an important role for such decisions.

\section{Conclusion}

The study provides an increased understanding of customer utilization of virtual channels. By investigating channel utilization for different types of activities based on objective data for channel use, it extends prior research, which has predominantly addressed the aggregate utilization of channels, often relying on self-reported channel use by consumers. 
Overall, the study contributes to Operations Management knowledge concerning the design of multichannel service delivery systems (Roth and Menor, 2003), namely the decisions about which activities to offer through virtual channels. While multichannel service providers operate multiple channels, they do not need to offer all activities in all channels; and even when they do so, they may choose to have different levels of resources allocated to supporting a given activity across different channels (for example, if customers do not value executing a given activity through a given virtual channel, the provider may nevertheless choose to offer it in that channel, but commit fewer resources to it). The study answers calls for an increased understanding of the alignment between the "voice of the user" and the "voice of the provider" (Chase and Apte, 2007; Cho and Menor, 2010).

\section{Acknowledgment}

This study was funded by the Government of the Portuguese Republic through the Foundation for Science and Technology, under grant number PTDC/EGEGES/101390/2008.

Financiamento de Fundos Estruturais e de Fundos Nacionais do MCTES

FCT Fundação para a Ciência e a Tecnologia MINISTÉRIO DA CIÊNCIA, TECNOLOGIA E ENSINO SUPERIOR

\section{References}

Black, N., Lockett, A., Ennew, C., Winklhofer, H., McKechnie, S. (2002), "Modelling consumer choice of distribution channels: An illustration from financial services", International Journal of Bank Marketing, Vol. 20, No. 4, pp. 161-173.

Boyer, K. and Frohlich, M. (2006), “Analysis of effects of operational execution on repeat purchasing for heterogeneous customer segments”, Production and Operations Management, Vol. 15, No. 2, pp. 229242.

Boyer, K. K., Hallowell, R., Roth, A. (2002), "E-services: operating strategy--a case study and a method for analyzing operational benefits", Journal of Operations management, Vol. 20, No.2, pp. 175-188.

Burke, R. R. (2002), "Technology and the customer interface: what consumers want in the physical and virtual store", Journal of the Academy of Marketing Science, Vol. 30, No. 4, pp. 411-432.

Chase, R., Apte, U. (2007), “A history of research in service operations: What's the big idea?", Journal of Operations Management, Vol. 25, No. 2, pp. 375-386.

Cho, Y., Menor, L. (2010), "Toward a provider-based view on the design and delivery of quality e-service encounters", Journal of Service Research, Vol. 13, No. 1, pp. 83-95.

Cho, S., Park, K. (2003), "Characteristics of product/service process and customer needs of geographical accessibility in electronic commerce", International Journal of Service Industry Management, Vol. 14, No. 5, pp. $520-538$.

Coelho, F., Easingwood, C. (2008), “A model of the antecedents of multiple channel usage”, Journal of Retailing and Consumer Services, Vol. 15, No. 1, pp. 32-41.

Dabholkar P. (2000), "Technology in service delivery: implications for self-service and service support", In: Iacobucci D, Swartz TA, editors. Handbook of services marketing and management. Thousand Oaks, CA: Sage Publications, 2000, 103-110.

Dabholkar, P. and Bagozzi, R. (2002), "An attitudinal model of technology-based self-service: Moderating effects of consumer traits and situational factors," Journal of the Academy of Marketing Science, Vol. 30, No. 3, pp. 184-201. 
Dholakia, U. M., Bagozzi, R. P., Pearo, L.K. (2004). "A social influence model of consumer participation in network-and small-group-based virtual communities", International Journal of Research in Marketing, Vol. 21, No. 3, pp. 241-263.

Dholakia, U., Kahn, B., Reeves, R., Rindfleisch, A., Stewart, D., Taylor, E. (2010), "Customer behavior in multichannel multimedia retailing environment, Journal of Interactive Marketing, Vol. 24, No. 2, pp. 86-95.

Ding, X., Verma, R., Iqbal, Z. (2007), "Self-service technology and online financial service choice", International Journal of Service Industry Management, Vol. 18, No. 3, pp. 246-268.

Frambach, R., Roest, H., Krishnan, T. (2007), "The impact of consumer internet experience on channel preference and usage intentions across the different stages of the buying process", Journal of Interactive Marketing, Vol. 21, No. 2, pp. 26-41.

Gensler, S., Dekimpe, M., Skiera, B. (2007), "Evaluating channel performance in multichannel environments", Journal of Retailing and Consumer Services, Vol. 14, No. 1, pp. 17-23.

Goodhue, D. L. (1995), "Understanding user evaluations of information systems", Management Science, Vol. 41, No. 12, pp. 1827-1844.

Goodhue, D. L., \& Thompson, R. L. (1995), "Task-technology fit and individual performance", MIS Quarterly, Vol. 19, No. 2, pp. 213-236.

Haynes, R. M. (1990),"Service Typologies: A Transaction Modelling Approach", International Journal of Service Industry Management, Vol. 1, No. 1, pp. 15 - 26.

Iqbal, Z., Verma, R., Baran, R. (2003), "Understanding consumer choices and preferences in transactionbased e-services", Journal of Service Research, Vol. 6, No. 1, pp. 51-65.

Lengel, R. H., Daft, R. L. (1988), "The selection of communication media as an executive skill”, Academy of Management Executive, Vol. 2, No. 3, pp.225-233.

McKnight, D., Choudhury, V., Kumar, C. (2002), "Developing and validating trust measures for ecommerce: An integrative typology", Information Systems Research, Vol. 13, No. 3, pp. 334-359.

Meuter, M. L., Ostrom, A. L., Roundtree, R.I., Bitner, M.J. (2000). "Self-service technologies: understanding customer satisfaction with technology-based service encounters", Journal of Marketing, Vol. 64, No. 3, pp. 50-64.

Monsuwé, T., Dellaert, B., Ruyter, K. (2004), "What drives consumers to shop online? A literature review”, International Journal of Service Industry Management, Vol. 15, No. 1, pp. 102-121.

Patrício, L., Fisk, R. P., Falcão e Cunha, J. (2011), "Multilevel Service Design: From Customer Value Constellation to Service Experience Blueprinting", Journal of Service Research, Vol. 14, No. 2, pp. 180-200.

Patrício, L., Fisk, R. P., Falcão e Cunha, J. (2008), "Designing multi-interface service experiences", Journal of Service Research, Vol. 10, No. 4, pp. 318-334.

Patrício, L., Fisk, R. P., Falcão e Cunha, J. (2003), "Improving satisfaction with bank service offerings: measuring the contribution of each delivery channel", Managing Service Quality, Vol. 13, No. 6, pp. $471-482$.

Pieterson, W., Van Dijk , J. (2007), "Channel Choice Determinants; An exploration of the factors that determine the choice of a service channel in citizen initiated contacts", In Proceedings of the 8th annual international conference on digital government research: Bridging disciplines and domains (Philadelphia, Pennsylvania, May 20-23, 2007)

Rice, R. E. (1992), "Task analyzability, use of new media, and effectiveness: A multi-site exploration of media richness", Organization Science, Vol. 3, No. 4, pp. 475-500.

Roth, A., Menor, L. (2003), "Insights into service operations management: A research agenda", Production and Operations Management, Vol. 12, No. 4, pp. 145-164.

Schoenbachler, D., Gordon, G. (2002), "Multi-channel shopping: understanding what drives channel choice", Journal of Consumer Marketing, Vol. 19, No. 1, pp. 42-53.

Seiders, K., Berry, L., Gresham, L. (2000), “Attention retailers! How convenient is your convenience strategy?, Sloan Management Review, Vol. 41, No. 3, pp. 79-89.

Seiders, K, Voss, G., Godfrey, A. and Grewal, D. (2007), "SERVCON: development and validation of a multidimensional service convenience scale", Journal of the Academy of Marketing Science, Vol. 35, No. 1, pp. 144-156.

Tse, A., Yim, F. (2001), "Factors affecting the choice of channels online vs conventional", Journal of International Consumer Marketing, Vol. 14, No. 2/3, pp. 137-152. 
van Birgelen, M., Jong, A., Ruyter, K. (2006), "Multi-channel service retailing: The effects of channel performance satisfaction on behavioural intentions", Journal of Retailing, Vol. 82, No. 4, pp. 367-377.

Venkatesan, R., Kumar, V., Ravishanker, N. (2007), "Multichannel shopping: Causes and consequences", Journal of Marketing, Vol. 71, No. 2, pp.114-132.

Weltevreden, J. W. J. (2007), "Substitution or complementarity? How the Internet changes city centre shopping", Journal of Retailing and Consumer Services, Vol. 14, No. 3, pp. 192-207.

van Birgelen, M., Jong, A., Ruyter, K. (2006), "Multi-channel service retailing: The effects of channel performance satisfaction on behavioural intentions", Journal of Retailing, Vol. 82, No. 4, pp. 367-377.

Xue, M., Hitt, L. M., Chen, P. (2011), "Determinants and outcomes of internet banking adoption", Management Science, Vol. 57, No. 2, pp. 291-307.

Xue, M., Hitt, L., Harker, P. (2007), "Customer efficiency, channel usage, and firm performance in retail banking”, Manufacturing \& Service Operations Management, Vol. 9, No. 4, pp. 535-558.

Zigurs, I., \& Buckland, B. K., (1998), "A theory of task/technology fit and group support system effectiveness", MIS Quarterly, Vol. 22, No. 3, pp. 313-334. 